\title{
Desempenho de vacas Girolando mantidas em pastejo de Tifton 85 irrigado ou sequeiro
}

\author{
[Performance of crossbred Holstein x Zebu cows rotationally grazing in Tifton 85 pasture \\ irrigated or rainfed]
}

\author{
A.M. Teixeira ${ }^{1}$, D.G. Jayme ${ }^{2}$, G.A. Sene ${ }^{3}$, L.O. Fernandes ${ }^{4}$, A.C. Barreto ${ }^{3}$, D.J. Rodrigues Júnior ${ }^{3}$, \\ A.C. Coutinho ${ }^{3}$, J.R. Glória \\ ${ }^{1}$ Faculdade de Medicina Veterinária - Universidade Federal de Uberlândia - Uberlândia, MG \\ ${ }^{2}$ Escola de Veterinária - Universidade Federal de Minas Gerais - Belo Horizonte, MG \\ ${ }^{3}$ Instituto Federal de Educação, Ciência e Tecnologia do Triângulo Mineiro (IFTM) - Uberaba, MG \\ ${ }^{4}$ Empresa de Pesquisa Agropecuária de Minas Gerais - Epamig - Belo Horizonte, MG \\ ${ }^{5}$ Instituto de Ciências Agrárias - UFMG - Montes Claros, MG
}

\begin{abstract}
RESUMO
Objetivou-se com este trabalho avaliar a taxa de lotação e a produção de leite de vacas mestiças Holandês $\mathrm{x}$ Zebu em pastagens de Tifton 85 irrigadas e em sequeiro, em Uberaba-MG. Os dados foram analisados em um delineamento de blocos inteiramente ao acaso, com três repetições por tratamento, num esquema fatorial $2 \times 10$ (dois tratamentos e 10 épocas). Foi utilizado um lote de 11 vacas em lactação por tratamento para avaliação do desempenho animal. As médias foram comparadas por meio do teste de Scott-Knott ao nível de $5 \%$ de probabilidade $(\mathrm{P}<0,05)$. A pastagem foi manejada em sistema de pastejo rotacionado com três e cinco dias de ocupação e 21 e 35 dias de descanso no período das águas e da seca, respectivamente. A taxa de lotação média do sistema irrigado, no período avaliado, foi de 4,6 UA.ha-1 ${ }^{-1}$, valor superior $(\mathrm{P}<0,05)$ à taxa média de 2,2 UA.ha ${ }^{-1}$ observada para o sistema de sequeiro. Não houve diferenças nas produções diárias de leite das vacas $(\mathrm{P}<0,05)$. A produção de leite média obtida no sistema irrigado foi de 51,7 litros. ha $^{-1} \cdot$ dia $^{-1}$. A irrigação possibilitou uma considerável intensificação do sistema, na medida em que proporcionou uma taxa de lotação bastante superior ao sistema de sequeiro.
\end{abstract}

Palavras-chave: Cynodon, irrigação, manejo, produção de leite

\begin{abstract}
The aim of this study was to determine the stocking rates and milk production of crossbred Holstein $x$ Zebu cows managed under irrigated or rainfed Tifton 85 pastures in Uberaba-MG. The statistical design adopted was completely randomized blocks with three repetitions per treatment, in a $2 \times 10$ factorial arrangement (2 treatments and 10 seasons). The average was compared using the Scott-Knott test with $5 \%$ probability $(P<0.05)$. To evaluate animal performance, 11 lactating cows per treatment were used. The pasture was managed in a rotational grazing system with 21 and 35 days of grazing interval and 3 and 5 days of grazing in each paddock, in the rainy and dry seasons respectively. The stocking rate of the irrigated system was 4.6 UA.ha-1 and was superior $(p<0.05)$ to the stocking rate of the rainfed system that was 2.2 UA.ha-1. There were no differences among the systems ( $p>0.05)$ for the average daily milk yield of the cows. In the irrigated system the average milk yield was 51.7 liters.ha-1.dia-1. With irrigation, a considerable intensification of the system was possible because it provided a superior stocking rate capacity compared to the rainfed system.
\end{abstract}

Keywords: Cynodon, grazing management, irrigation, milk yield

Recebido em 11 de março de 2012

Aceito em 5 de maio de 2013

E-mail: alexmteixeira@yahoo.com.br 


\section{INTRODUÇÃO}

Diante das pressões de uma agricultura intensiva praticada no país, da elevação dos preços da terra e dos insumos e das questões ambientais e sociais, os produtores têm sido incentivados e, ao mesmo tempo, pressionados a buscar um processo de verticalização do sistema de produção e, consequentemente, maior competitividade, sustentabilidade e consolidação da atividade de pecuária de leite.

Apesar de não haver estatísticas precisas sobre a contribuição de cada sistema - em pasto, misto e em confinamento - na produção total de leite no país, sabe-se que as pastagens representam a principal fonte de alimento volumoso em grande parte dos sistemas. Sendo assim, pode-se inferir que baixas produtividades frequentemente verificadas são reflexo de sistemas com condições inadequadas de manejo das pastagens.

Neste cenário atual, a intensificação da produção de leite em pastagens se torna uma solução viável para propriedades leiteiras. Contudo, essa intensificação se depara com a estacionalidade da produção de forragem ao longo do ano. Soares Filho et al. (2002) encontraram que algumas gramíneas dos gêneros Cynodon, Brachiaria e Panicum concentraram aproximadamente $85 \%$ da produção anual de matéria seca no período chuvoso. Com o intuito de reduzir essa estacionalidade, alguns sistemas de produção animal a pasto têm feito uso da irrigação. No país, apenas 3,2 milhões de hectares (5\% da área utilizada) são irrigados, apesar de essa pequena parcela responder por $16 \%$ da produção total e $35 \%$ do valor econômico (Mendonça et al., 2010).

Há que se ressaltar que, caso os demais fatores climáticos, que determinam a produção de forragem, estejam deficientes, haverá pouco ou nenhum ganho por meio da irrigação. Como exemplo, pode-se citar a temperatura, a qual deveria estar entre 30 e $35^{\circ} \mathrm{C}$ para o ótimo desenvolvimento de gramíneas tropicais. A temperatura-base inferior, abaixo da qual não há crescimento, varia de 12 a $17,5^{\circ} \mathrm{C}$ (Mendonça et al., 2010). Porém, a espécie de gramínea Cynodon dactylon cv. Tifton-85, segundo Vilela e Alvim (1996), desde que tenha condições adequadas de fertilidade e umidade, continua a se desenvolver em dias curtos e frios até o limite de $4^{\circ} \mathrm{C}$.

As gramíneas do gênero Cynodon estão sendo intensivamente pesquisadas no Brasil, principalmente devido às suas vantagens nutricionais, ao potencial produtivo, à resposta à fertilização, à capacidade de adaptação a diferentes ambientes e à flexibilidade de uso. Resultados de pesquisa da Embrapa Gado de Leite têm mostrado grande potencial destas gramíneas para uma produção de leite a pasto de forma intensiva e racional, com produção de leite diária de até $104 \mathrm{~kg}$.ha ${ }^{-1}$ e com taxas de lotação de cinco a sete vacas.ha ${ }^{-1}$ (Alvim et al., 1997; Vilela et al., 1996, 2002, 2006, 2007).

Realizou-se este estudo com o objetivo de avaliar a taxa de lotação e o desempenho produtivo de vacas de leite mestiças Holandês x Gir leite em pastagens de Tifton 85 irrigadas ou em sequeiro sob lotação rotacionada.

\section{MATERIAL E MÉTODOS}

O experimento foi desenvolvido na Fazenda Santa Rosa, unidade de ensino e pesquisa do Instituto Federal do Triângulo Mineiro - campus Uberaba, no município de Uberaba/MG (latitude $19^{\circ} 39^{\prime} 8^{\prime \prime} \mathrm{S}$, longitude $47^{\circ} 57^{\prime} 8^{\prime \prime} \mathrm{W}$ e altitude de $825 \mathrm{~m}$ ), em solo do tipo Latossolo Vermelho Amarelo distrófico, de agosto de 2008 a agosto de 2009. Foi utilizada uma área de Tifton 85 estabelecida há dois anos, na qual foi realizado um corte de uniformização em outubro de 2007.

Foram utilizadas 22 vacas mestiças Holandês $\mathrm{x}$ Gir, com peso vivo médio de $530 \mathrm{~kg}$ e potencial para produção de $4200 \mathrm{~kg} / \mathrm{lactação,} \mathrm{mantidas} \mathrm{em}$ uma área de 10,56ha. Para a alocação dos animais nos tratamentos, foram considerados o grau de sangue, a produção de leite, a ordem de parto e o período de lactação, sendo distribuídos animais semelhantes no sistema irrigado e no sistema sequeiro. Repetiu-se este procedimento até a alocação de 11 animais em cada tratamento.

Os tratamentos foram constituídos de pastagem de Tifton 85 manejada em condições de sequeiro e pastagem de Tifton 85 manejada em condições de irrigação. Para cada tratamento foi utilizada uma área de 5,28ha, dividida em três blocos, sendo que cada bloco continha oito piquetes de $0,22 \mathrm{ha}$, divididos por cerca elétrica. 
As pastagens foram manejadas em condições de lotação rotacionada e receberam adubação para permitir taxa de lotação de 7 UA.ha $^{-1}$ durante o período das águas. O sistema rotacionado foi manejado com três dias de ocupação e 21 de descanso no período chuvoso e cinco dias de ocupação e 35 de descanso no período seco do ano. Para o ajuste da taxa de lotação, realizou-se a pesagem de todos os animais quinzenalmente. Em cada sistema manteve-se um lote fixo de 11 vacas em lactação para efeito de avaliação do desempenho animal.

Foram utilizados animais extras (put and take) conforme Mott e Lucas (1952), para ajustar a oferta de forragem, de modo a se obter uma oferta de matéria seca de 5 e $7 \%$ do peso vivo médio, na época das águas e na época da seca, respectivamente.

As pastagens receberam adubação de $300 \mathrm{~kg} \cdot \mathrm{ha}^{-1}$. ano ${ }^{-1}$ da fórmula 20-05-20, distribuída a lanço em seis aplicações anuais, sempre após a saída dos animais dos piquetes.

Foi utilizado um sistema de irrigação em malha, manejado com turno de rega fixo e realizado sempre que os animais haviam saído dos piquetes. A determinação da lâmina de água a ser aplicada era realizada de acordo com dados de umidade do solo coletados um dia antes da saída dos animais, e o valor da umidade de capacidade de campo era determinado seguindo a metodologia proposta por Bernardo (1989).

A forragem disponível foi estimada considerando-se a quantidade de forragem cortada antes da entrada dos animais, ao nível do solo, constante no interior de um quadrado metálico com $1 \mathrm{~m}$ de lado, lançado ao acaso quatro vezes em cada piquete. Após o corte, o material colhido foi homogeneizado e pesado, sendo obtida a massa de forragem verde. Foi retirada uma subamostra dessa forragem, de aproximadamente $300 \mathrm{~g}$, para determinação da matéria pré-seca em estufa de ventilação forçada a $55^{\circ} \mathrm{C}$ por 72 horas. O material pré-seco foi moído em moinho estacionário do tipo Willey, utilizando-se peneira de 1 (um) milímetro, e armazenado em recipientes de poetileno com tampa. Nas amostras de forragem foram executadas análises, em duplicatas, de matéria seca (MS) em estufa a $105^{\circ} \mathrm{C}$ (AOAC, 1980). A massa de forragem, em $\mathrm{kg} / \mathrm{ha}$ de $\mathrm{MS}$, foi determinada multiplicando-se a biomassa de matéria verde pelo teor de MS da amostra.

A massa de forragem disponível/ha em cada ciclo de pastejo, período necessário para cada grupo de vacas pastejarem os oito piquetes, foi calculada pela média da biomassa de forragem obtida em cada um dos piquetes $(1,2,3,4,5,6$, 7 e 8) naquele ciclo de pastejo.

Durante o período das águas, os animais que produziram acima de $10 \mathrm{~kg}$ de leite.dia ${ }^{-1}$, nos dois sistemas, receberam suplementação com concentrado na quantidade de $1 \mathrm{~kg}$ de concentrado para cada $2,5 \mathrm{~kg}$ de leite produzido acima de $10,0 \mathrm{~kg}$ de leite.dia ${ }^{-1}$. O concentrado era composto de $51 \%$ de milho grão moído, $44 \%$ de farelo de soja e $5 \%$ de núcleo mineral, com composição química média de $26 \%$ de proteína bruta (PB) e $81 \%$ de nutrientes digestíveis totais (NDT). No período da seca, para o lote manejado no sistema irrigado, o volumoso continuou sendo a forragem da pastagem, porém passou a receber $1 \mathrm{~kg}$ do mesmo concentrado para cada $3,6 \mathrm{~kg}$ de leite produzido. O lote manejado na pastagem de sequeiro foi modificado, sendo composto neste período de vacas "secas", pois os animais em lactação apresentaram queda brusca de produção e perda de peso. As vacas em lactação do sistema sequeiro, neste período do ano, foram alimentadas em sistema de confinamento, sendo considerada inexistente a produção de leite no sistema de sequeiro.

Foram realizados controles leiteiros a cada 14 dias para determinação de produção de leite diária por vaca. $\mathrm{O}$ valor da produção de leite por área representou a média das produções diárias obtidas durante cada ciclo de pastejo multiplicada pela taxa de lotação.

Para a produção diária de leite por vaca, foi utilizado o delineamento fatorial 2x10 (tratamentos $\mathrm{x}$ épocas), inteiramente ao acaso, com 11 repetições (vacas em lactação). Para a biomassa de forragem, a taxa de lotação e a produção de leite por área, utilizou-se o delineamento fatorial $(2 \times 10)$ em blocos ao acaso.

Os dados foram submetidos à análise de variância, utilizando-se o pacote estatístico software SAS (Statistical..., 1993), e as médias foram comparadas pelo teste Scott-Knott $(\mathrm{P}<0,05)$. 


\section{RESULTADOS E DISCUSSÃO}

Os dados climáticos, relativos ao período experimental, foram coletados na Estação Meteorológica da Companhia Energética de Minas Gerais, localizada a aproximadamente $2 \mathrm{~km}$ do local do experimento (Fig. 1).
É possível observar que a estação chuvosa se concentrou de setembro a maio, apesar de os dados de precipitação dos meses de novembro, abril e maio serem inferiores a $100 \mathrm{~mm}$. A partir do mês de abril, as temperaturas mínimas registradas na região do experimento estavam abaixo de $15^{\circ} \mathrm{C}$.

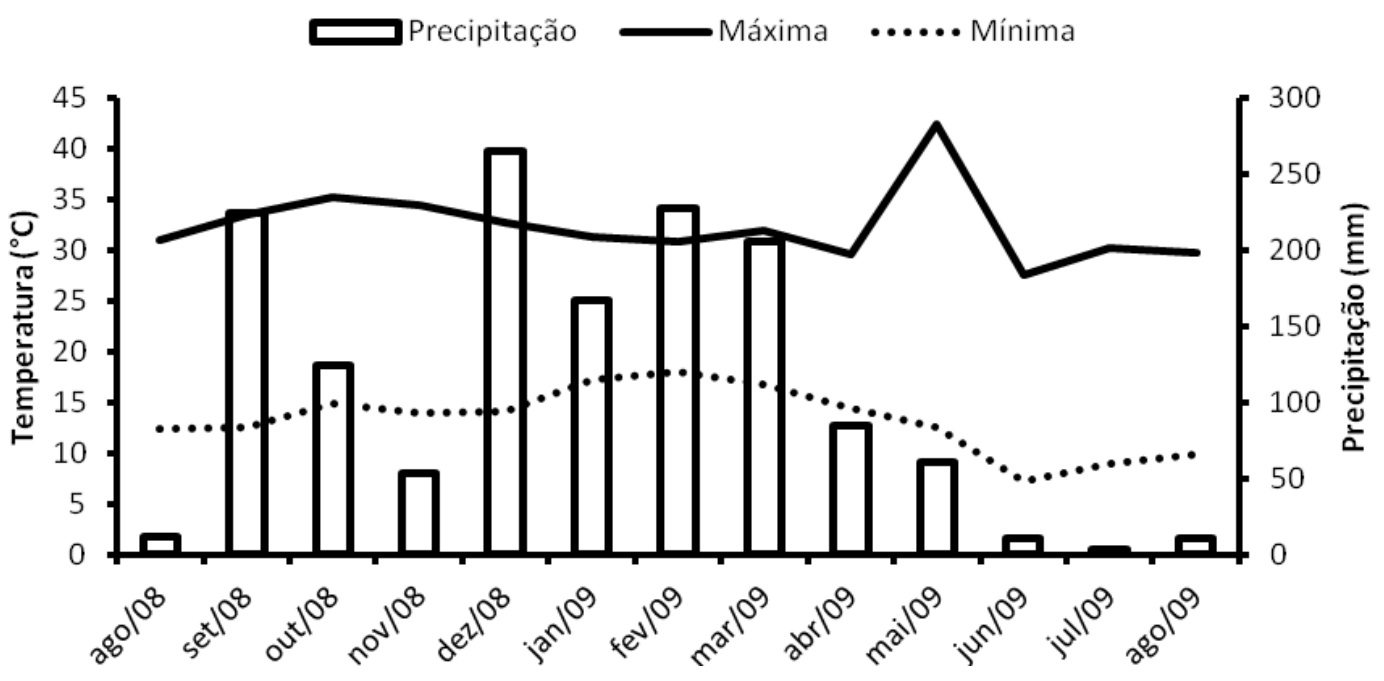

Figura 1. Dados médios climatológicos da região no período experimental.

Em virtude da estacionalidade da produção de forragem observada em todas as regiões do país, foi estimada a forragem disponível em pastagens de Tifton 85 irrigado e sequeiro ao longo do ano (Tab. 1).

Tabela 1. Biomassa de matéria seca $\left(\mathrm{kg} \cdot \mathrm{ha}^{-1}\right)$ em pastagens de Tifton 85 manejadas em condições de irrigação e sequeiro

\begin{tabular}{lccc}
\hline Ciclo & Época & Irrigado & Sequeiro \\
\hline 1 & ago-set 08 & $3234,4 \mathrm{Ac}$ & $2275,8 \mathrm{Ab}$ \\
2 & out-nov 08 & $3154,1 \mathrm{Ac}$ & $2691,8 \mathrm{Aa}$ \\
3 & nov-dez 08 & $3900,9 \mathrm{Ab}$ & $3233,1 \mathrm{Aa}$ \\
4 & dez-jan 09 & $6129,7 \mathrm{Aa}$ & $3352,3 \mathrm{Ba}$ \\
5 & jan-fev 09 & $4789,9 \mathrm{Ab}$ & $3711,3 \mathrm{Aa}$ \\
6 & fev-mar 09 & $4033,1 \mathrm{Ab}$ & $2790,5 \mathrm{Ba}$ \\
7 & mar-abr 09 & $2577,8 \mathrm{Ac}$ & $2034,2 \mathrm{Ab}$ \\
8 & mai 09 & $2753,5 \mathrm{Ac}$ & $1726,1 \mathrm{Ab}$ \\
9 & jun 09 & $2501,3 \mathrm{Ac}$ & $1762,7 \mathrm{Ab}$ \\
10 & jul-ago 09 & $2207,6 \mathrm{Ac}$ & $2115,0 \mathrm{Ab}$ \\
Média & & $3538,2 \mathrm{~A}$ & $2569,3 \mathrm{~B}$ \\
\hline
\end{tabular}

Médias seguidas por letras minúsculas distintas na mesma coluna e letras maiúsculas na mesma linha diferem entre si pelo teste de Scott-Knott a $5 \%$ de probabilidade. Coeficiente de variação $=21,99 \%$.
No sistema irrigado, a maior disponibilidade de MS de forragem foi verificada no quarto ciclo de pastejo (dez-jan 08) $(\mathrm{P}<0,05)$. Para o sistema de sequeiro, os valores de forragem disponível do segundo ao sexto ciclo de pastejo (período chuvoso, Fig. 1) foram semelhantes $(\mathrm{P}>0,05)$ e superiores $(\mathrm{P}<0,05)$ aos demais ciclos. Entre os sistemas, o irrigado apresentou valores superiores ao sistema de sequeiro apenas no quarto e sexto ciclos de pastejo $(\mathrm{P}<0,05)$.

Comportamento semelhante foi observado por Balieiro Neto et al. (2007), que não observaram diferenças entre a massa de forragem disponível em pastagens de Tifton 85 irrigado e sequeiro. Os valores de disponibilidade de forragem obtidos no presente experimento são inferiores aos descritos por esses autores, de $10.761 \mathrm{~kg}$ de MS.ha ${ }^{-1}$ para o Tifton 85 , manejado também em lotação rotacionada, porém com 28 dias de descanso. A partir do sétimo ciclo de pastejo (mar-abr), foram obtidas as menores disponibilidades de forragem em ambos os sistemas, coincidindo períodos nos quais foram 
registradas temperaturas mínimas abaixo de $15^{\circ} \mathrm{C}$ (Fig. 1).

Na Tab. 2, são apresentadas as taxas de lotação médias em pastagens de Tifton 85 irrigado e sequeiro.

Tabela 2. Taxa de lotação $\left(\right.$ UA.ha $\left.^{-1}\right)$ em pastagens de Tifton 85 manejadas em condições de irrigação e sequeiro

\begin{tabular}{lccc}
\hline Ciclo & Época & Irrigado & Sequeiro \\
\hline 1 & ago-set 08 & $1,6 \mathrm{Ad}$ & $1,2 \mathrm{Ad}$ \\
2 & out-nov 08 & $3,7 \mathrm{Ac}$ & $2,2 \mathrm{Bc}$ \\
3 & nov-dez 08 & $6,5 \mathrm{Aa}$ & $4,3 \mathrm{Ba}$ \\
4 & dez-jan 09 & $7,3 \mathrm{Aa}$ & $4,6 \mathrm{Ba}$ \\
5 & jan-fev 09 & $5,1 \mathrm{Ab}$ & $3,1 \mathrm{Bb}$ \\
6 & fev-mar 09 & $3,1 \mathrm{Ac}$ & $2,3 \mathrm{Ac}$ \\
7 & mar-abr 09 & $4,8 \mathrm{Ab}$ & $1,4 \mathrm{Bd}$ \\
8 & mai 09 & $6,5 \mathrm{Aa}$ & $1,3 \mathrm{Bd}$ \\
9 & jun 09 & $4,7 \mathrm{Ab}$ & $1,2 \mathrm{Bd}$ \\
10 & jul-ago 09 & $2,5 \mathrm{Ad}$ & $0,9 \mathrm{Bd}$ \\
Média & & $4,6 \mathrm{a}$ & $2,2 \mathrm{~B}$ \\
\hline
\end{tabular}

Médias seguidas por letras minúsculas distintas na mesma coluna e letras maiúsculas na mesma linha diferem entre si pelo teste de Scott-Knott a $5 \%$ de probabilidade. Coeficiente de variação $=35,81 \%$.

A taxa de lotação média do sistema irrigado, no período avaliado, foi de 4,6 UA.ha ${ }^{-1}$, valor superior $(\mathrm{P}<0,05)$ à taxa média de 2,2 UA.ha ${ }^{-1}$ observada para o sistema de sequeiro. No sistema irrigado, os maiores $(\mathrm{P}<0,05)$ valores obtidos para a taxa de lotação foram de 6,5, 7,3 e 6,5 UA.ha ${ }^{-1}$, sendo observadas nos ciclos de pastejo 3 (nov-dez 08), 4 (dez-jan 09) e 8 (mai 09), respectivamente. Uma provável explicação para a alta taxa de lotação observada em junho seria o fato de que neste mês foi verificado o maior valor de temperatura máxima de todo o período de avaliação (Fig. 1). Em relação ao sistema de sequeiro, as maiores taxas de lotação foram observadas entre novembro de 2008 e janeiro de 2009, coincidindo com o período no qual foi registrado o maior volume de chuvas na região durante o período experimental (Fig. 1). Entre os sistemas, o irrigado se mostrou superior $(p<0,05)$ ao sequeiro na grande maioria dos períodos de avaliação, com exceção dos ciclos de pastejo 1 (ago-set 08) e 6 (fev-mar 09).

Em pastagens de coast-cross irrigadas, Vilela et al. (2006) trabalharam com taxa de lotação de aproximadamente 6 UA.ha $^{-1}$, valor superior ao do presente experimento, porém com nível de suplementação concentrada de 3 e $6 \mathrm{~kg}$.animal ${ }^{-}$ ${ }^{1} \cdot \mathrm{dia}^{-1}$. Semelhante aos valores do presente estudo, Porto et al. (2009) encontraram taxa de lotação superior a 4,0 vacas/ha na época das águas, ao trabalharem com pastagens de gramíneas tropicais manejadas em lotação rotacionada e sem suplementação de concentrado. Segundo Deresz (2001a), forrageiras tropicais, quando são bem manejadas, têm suportado taxas de lotação de 4,5 vacas.ha ${ }^{-1}$ durante o período das águas, quando se trabalha com vacas mestiças Holandês x Zebu com potencial de produção de 4000 a $4500 \mathrm{~kg}$ de leite.lactação ${ }^{-1}$ sem suplementação concentrada.

A Tab. 3 apresenta os dados de produção de leite, que, devido a algumas falhas ocorridas no manejo da ordenha, passaram a ser mensurados a partir de março de 2009.

Tabela 3. Produção diária de leite por vaca (litros.vaca ${ }^{-1} \cdot$ dia $^{-1}$ ) em pastagens de Tifton 85 manejadas em condições de irrigação e sequeiro ou confinadas*

\begin{tabular}{|c|c|c|c|c|}
\hline Ciclo & Época & Irrigado & Sequeiro & Confinamento \\
\hline 6 & fev-mar 09 & $15,0 \mathrm{Aa}$ & $13,5 \mathrm{Aa}$ & --- \\
\hline 7 & mar-abr 09 & $13,2 \mathrm{Aa}$ & $11,8 \mathrm{Aa}$ & --- \\
\hline 8 & mai 09 & 9,9Ab & 11,9Aa & --- \\
\hline 9 & jun 09 & $7,8 \mathrm{Bb}$ & --- & $11,3 \mathrm{Aa}^{*}$ \\
\hline 10 & jul-ago 09 & $9,6 \mathrm{Ab}$ & --- & $10,9 \mathrm{Aa}^{*}$ \\
\hline Média & & $11,1 \mathrm{~A}$ & & \\
\hline
\end{tabular}

Médias seguidas por letras minúsculas distintas na mesma coluna e letras maiúsculas na mesma linha diferem entre si pelo teste de Scott-Knott a 5\% de probabilidade. *As vacas do sistema de sequeiro foram transferidas para o confinamento e receberam silagem de milho e mesma quantidade e composição do concentrado das vacas em pasto. Coeficiente de variação $=33,09 \%$. 
As maiores produções diárias de leite observadas no sistema irrigado ocorreram durante os ciclos de pastejo 6 e $7(\mathrm{P}<0,05)$. No mês de maio (ciclo 8 ), a produção média diária de leite das vacas manejadas no sistema irrigado reduziu em relação ao ciclo anterior $(\mathrm{P}<0,05)$, mantendo-se estável até o final do período de avaliação. Apesar de haver o fornecimento de água para a forrageira por meio da irrigação, a partir do mês de maio de 2009 foram verificados os mais baixos valores de temperatura mínima (Fig. 1), o que, associado a alterações na intensidade da luminosidade do dia, interfere na estrutura da pastagem, refletindo, assim, na qualidade da forragem e, consequentemente, no desempenho dos animais.

Não houve diferenças $(\mathrm{P}>0,05)$ nas produções diárias de leite dos animais mantidos no sistema de sequeiro. Contudo, a partir do mês de junho, para evitar que houvesse queda da produção de leite e/ou perda de condição corporal, as vacas do sistema sequeiro foram transferidas para o confinamento e passaram a receber silagem de milho. Nos piquetes do sistema de sequeiro neste período, permaneceram apenas vacas secas, para prosseguir com a avaliação da taxa de lotação. Entre os sistemas, não houve diferença quanto ao desempenho dos animais $(\mathrm{P}>0,05)$, exceto no nono ciclo de pastejo (jun 09), quando a produção dos animais do sistema de sequeiro foi superior à dos animais do sistema irrigado $(\mathrm{P}<0,05)\left(10,9 \times 7,8 \mathrm{~kg}\right.$ de leite.vaca $\left.{ }^{-1} \cdot \mathrm{dia}^{-1}\right)$. Este período coincidiu com o início do fornecimento da silagem de milho aos animais do sistema de sequeiro.

Fukumoto et al. (2010) encontraram produção média inferior ao do presente estudo, com valores de 9,1, 9,1 e 8,7 litros.vaca ${ }^{-1} \cdot$ dia $^{-1}$, para vacas mestiças Holandês x Zebu que receberam $2 \mathrm{~kg}$ de concentrado por dia, manejadas sob regime de lotação rotacionada em pastagens de capim-tanzânia, grama-estrela e capim-marandu, respectivamente. Vilela et al. (2006) observaram produções variando de 12,0 a 19,1 litros.vaca ${ }^{1}$.dia ${ }^{-1}$, em função do estádio de lactação, para vacas da raça Holandesa manejadas em pastagens de coast-cross irrigadas, com suplementação de $3 \mathrm{~kg}$ de concentrado por dia. Semelhante ao presente estudo, Deresz (2001b) relatou pico de produção de $15,1 \mathrm{~kg}$ de leite.vaca ${ }^{1}$.dia ${ }^{-1}$ para animais manejados em pastagens de capim-elefante e suplementados com $2 \mathrm{~kg}$ de concentrado.

Segundo Favoretto et al. (2008), em condição de pastejo rotacionado com intervalo de descanso de 30 dias, pastagens de grama-estrela cv. africana suplementadas com $2 \mathrm{~kg}$ de concentrado atendem à demanda nutricional de mantença e produção de $11,7 \mathrm{~kg}$ de leite.vaca ${ }^{-1} \cdot \mathrm{dia}^{-1}$, valor este muito próximo ao obtido neste estudo tanto para o sistema irrigado quanto de sequeiro. Quando há suplementação concentrada, segundo Vilela et al. (2007), pastagens do gênero Cynodon, neste caso coast-cross, seriam capazes de suprir as exigências nutricionais de vacas da raça Holandesa com produção de até 19,1 litros.vaca ${ }^{-1} \cdot \mathrm{dia}^{-1}$, possibilitando taxa de lotação de cinco vacas.ha ${ }^{-1}$.

Houve variação da produção de leite por área em função da época de avaliação (Tab. 4), refletindo as diferenças observadas nas taxas de lotação (Tab. 2) bem como na produção diária de leite dos animais mantidos no sistema irrigado (Tab. 3).

Tabela 4. Produção de leite por área (litros. ha ${ }^{-1} \cdot \mathrm{dia}^{-1}$ ) em pastagens de Tifton 85 manejadas em condições de irrigação

\begin{tabular}{lcc}
\hline Ciclo & Época & Irrigado \\
\hline 6 & fev-mar 09 & $75,7 \mathrm{a}$ \\
7 & mar-abr 09 & $40,3 \mathrm{c}$ \\
8 & mai 09 & $47,6 \mathrm{~b}$ \\
9 & jun 09 & $50,4 \mathrm{~b}$ \\
10 & jul-ago 09 & $44,7 \mathrm{c}$ \\
Média & & 51,7 \\
\hline
\end{tabular}

Médias seguidas por letras minúsculas distintas diferem entre si pelo teste de Scott-Knott a 5\% de probabilidade. Coeficiente de variação $=20,55 \%$.

A maior produção diária de leite por área foi observada durante o sexto (fev-mar 09) ciclo de pastejo $(\mathrm{P}<0,05)$. A produção de leite média obtida durante o período de avaliação foi de 51,7 litros. ha ${ }^{-1} \cdot \mathrm{dia}^{-1}$, o que possibilita uma produção estimada de aproximadamente 19.000 litros de leite.ha ${ }^{-1}$.ano ${ }^{-1}$. Alvim et al. (1997) relataram produção anual superior a $37.000 \mathrm{~kg}$ de leite.ha ${ }^{-1}$ em pastagens de coast-cross adubadas e irrigadas, com taxa de lotação de 5,1 vacas/ha e animais com potencial de produção de 6.000 a $7.000 \mathrm{~kg}$ leite.lactação ${ }^{-1}$. 


\section{CONCLUSÕES}

Pastagens de Tifton 85 irrigadas possibilitam uma taxa de lotação média durante o período de avaliação de 4,6 UA.ha ${ }^{-1}$, valor este aproximadamente $100 \%$ superior ao obtido no sistema de sequeiro. A produção diária de leite por área permite que o sistema obtenha uma produtividade estimada de 19.000 litros de leite.ha ${ }^{-1} \cdot$ ano $^{-1}$, quando da utilização de vacas com produção média de $4.200 \mathrm{~kg}$ de leite/lactação.

\section{AGRADECIMENTOS}

À Fapemig, pelo apoio financeiro, e à Cemig, ao IFTM e à Epamig, pela colaboração na realização do estudo.

\section{REFERÊNCIAS}

ALVIM, M.J.; VILELA, D.; LOPES, R.S. Efeito de dois níveis de concentrado sobre a produção de leite de vacas da raça Holandesa em pastagem de coastcross. Rev. Bras. Zootec., v.26, p.967-975, 1997.

ASSOCIATION Official Analytical Chemits. Official methods of analisys. 13.ed. Washington, D.C.: AOAC, 1015p., 1980.

BALIEIRO NETO, G.; FERREIRA， J.J..; FERREIRA, M.B.D. et al. Características agronômicas e viabilidade do tifton-85 (Cynodon spp) irrigado num sistema de produção de leite. Braz. J. vet. Res. anim. Sci., v.44, p.235-242, 2007.

BERNARDO, S. Manual de irrigação. 5.ed. Viçosa: UFV, 1989. 596p.

DERESZ, F. Influência do período de descanso da pastagem de capim-elefante na produção de leite de vacas mestiças Holandês x Zebu. Rev. Bras. Zootec., v.30, p.461-469, 2001a

DERESZ, F. Produção de Leite de Vacas Mestiças Holandês x Zebu em Pastagem de Capim-Elefante, Manejada em Sistema Rotativo com e sem Suplementação durante a Época das Chuvas. Rev. Bras. Zootec., v.30, p.197-204, 2001b.

FAVORETO, M.G.; DERESZ, F.; FERNANDES, A.M. et al. Avaliação nutricional da grama-estrela cv. Africana para vacas leiteiras em condições de pastejo. Rev. Bras. Zootec., v.37, p.319-327, 2008.
FUKUMOTO, N.M.; DAMASCENO, J.C.; DERESZ, F. et al. Produção e composição do leite, consumo de matéria seca e taxa de lotação em pastagens de gramíneas tropicais manejadas sob lotação rotacionada. Rev. Bras. Zootec., v.39, p.1548-1557, 2010

MENDONÇA, F.C.; SANTOS, P.M.; CAVALCANTE, A.C.R. Irrigação de pastagens. In: PIRES, A.V. (Ed.). Bovinocultura de corte. Piracicaba: FEALQ, 2010. p.473-508.

MOTT, G.O.; LUCAS, H.L. The design, conduct and interpretation of grazing trials on cultivated and improved pastures. In: INTERNATIONAL GRASSLAND CONGRESS, 6., 1952, Pensylvania. Proceedings... Pensylvania: State College Press, 1952. p.1380-1385.

PORTO, P.P.; DERESZ, F.; SANTOS, G.T.; et al. Produção e composição química do leite, consumo e digestibilidade de forragens tropicais manejadas em sistema de lotação intermitente. Rev. Bras. Zootec., v.38, p.1422-1431, 2009

STATISTICAL Analysis Sistem. SAS/STAT user's guide: statistics. 4.ed. Version 6. Cary, North Caroline, v.2, 1993. 943p.

SOARES FILHO, C.V.; RODRIGUES, L.R.; PERRI, S.H.V. Produção e valor nutritivo de dez gramíneas forrageiras na região Noroeste do Estado de São Paulo. Acta Sci., v.24, p.1377-1384, 2002.

VILELA, D.; ALVIM, M. J. V. Produção de leite em pastagem de "coast-cross". In: WORKSHOP SOBRE O POTENCIAL FORRAGEIRO DO GÊNERO CYNODON. 1996, Juiz de Fora. Anais ... Juiz de Fora: CNPGL, 1996. p.77-91.

VILELA, D.; ALVIM, M.J.; CAMPOS, O.F.; RESENDE, J.C. Produção de leite de vacas Holandesas em confinamento ou em pastagem de coastcross. Rev. Bras. Zootec., v.25, p.1228-1244, 1996.

VILELA, D.; ALVIM, M.J.; MATOS, L.L.; MATIOLLI, J.B. Utilização de gordura protegida durante o terço inicial da lactação de vacas leiteiras, em pastagem de coast-cross. Pesq. Agropec. Bras., v.37, p.1503-1509, 2002

VILELA, D.; LIMA， J.A.; RESENDE， J.C.; VERNEQUE, R.S. Desempenho de vacas da raça Holandesa em pastagem de coastcross. Rev. Bras. Zootec., v.35, p.555-561, 2006.

VILELA, D.; FERREIRA, A.M.; RESENDE, J.C. et al. Efeito do concentrado no desempenho produtivo, reprodutivo e econômico de vacas da raça Holandesa em pastagem de coast-cross. Arq. Bras. Med. Vet. Zootec., v.59, p.443-450, 2007. 